\title{
Monosialoteterahexosyl ganglioside induces the differentiation of human umbilical cord-derived mesenchymal stem cells into neuron-like cells
}

\author{
CHENGRUI NAN $^{1}$, YUNPENG SHI $^{1}$, ZONGMAO ZHAO $^{1}$, SHUCHENG MA $^{1}$, JIXIANG LIU ${ }^{2}$, \\ DONGDONG YAN ${ }^{1}$, GUOQIANG SONG ${ }^{1}$ and HANJIE LIU ${ }^{1}$ \\ ${ }^{1}$ Department of Neurosurgery, The Second Hospital of Hebei Medical University, Shijiazhuang, Hebei 050000; \\ ${ }^{2}$ The First Hospital of Handan City, Handan, Hebei 056000, P.R. China
}

Received June 8, 2015; Accepted July 24, 2015

DOI: $10.3892 / \mathrm{ijmm} .2015 .2307$

\begin{abstract}
In the present study, human umbilical cord-derived mesenchymal stem cells (hUMSCs) were investigated for their potential to be induced to differentiate in vitro into neuronlike cells by monosialoteterahexosyl ganglioside (GM1). Mononuclear cells obtained from umbilical cords from women with full-term pregnancies whose babies were delivered by cesarean section were cultivated in vitro and their surface antigen expression profiles were monitored. Following amplification, the cells were divided into 5 groups, of which 4 (groups A-D) were treated with GM1 at doses of 50, 100, 150 and $200 \mu \mathrm{g} /$ $\mathrm{ml}$, respectively. The control (group E) was treated with the vehicle only. The ability of GM1 to induce the differentiation of the hUMSCs into neuron-like cells was monitored for $6 \mathrm{~h}$. The expression levels of microtubule-associated protein-2 (MAP2 ), neurofilament protein (NF-H) and glial fibrillary acidic protein (GFAP) were measured by immunohistochemistry. Following exposure to GM1, the hUMSCs first appeared to have a diamond or polygonal shape and gradually grew into long spindle-shaped cells, finally exhibiting a radiating or swirling pattern. The cells maintained a strong proliferative capacity after continuous passage. Flow cytometry revealed that the hUMSCs expressed CD73, CD90 and CD105 up to passage 10, but not CD11b, CD19, CD34, CD45 or HLA-DR. Treatment with GM1 for $6 \mathrm{~h}$ led to the appearance of neuron-like cells with oval-shaped cell bodies and protruding neurites. These neuron-like cells were positive for MAP-2 and NF-H, but negative for GFAP expression. No changes in the expression of these markers were observed in the control group. Thus, the findings of the present study demonstrate that GM1 effectively induces hUMSCs to differentiate into neuron-like cells.
\end{abstract}

Correspondence to: Dr Zongmao Zhao, Department of Neurosurgery, The Second Hospital of Hebei Medical University, 215 Peace West Road, Shijiazhuang, Hebei 050000, P.R. China E-mail: zzm69@163.com

Key words: monosialoteterahexosyl ganglioside, human umbilical cord-derived mesenchymal stem cells, differentiation, neuron-like cells

\section{Introduction}

Mesenchymal stem cells (MSCs) are pluripotent stem cells, which are formed during the early development of the mesoderm. With a high capacity for self-renewal and the potential for multi-directional differentiation, these cells are present in several tissues and can also be cultured in vitro (1). Under defined specific culture conditions, these MSCs can be induced to differentiate into neuronal cells, osteoblasts, chondrocytes, muscle cells and fat cells. Therefore, MCSs hold great promise for use in cell replacement therapy and tissue engineering (1). Baksh et al (2) found that human umbilical cord-derived MSCs (hUCMSCs) have a strong proliferative and differentiation potential. As hUMSCs are obtained using non-invasive procedures, thus avoiding ethical restrictions, they are considered an ideal source of human-derived MSCs for use in clinical studies and research.

Gangliosides, a class of glycosphingolipids containing sialic acid, are present in the cell membrane of various cell types in vertebrates and are particularly present in high levels in the gray matter of the brain. Gangliosides are associated with nerve cell differentiation and the length of neurites, as well as the formation of synapses (3). Monosialoteterahexosyl ganglioside (GM1) is a major ganglioside species in mammals, and it has been shown that the application of exogenous GM1 promotes cell regeneration in the nervous system and the formation of synapses (4). In the present study, we demonstrate that GM1 is effective in inducing the differentiation of hUMSCs into neuron-like cells in vitro. We further investigated the related mechanisms and observed that the expression of several markers of neuronal cells was induced by GM1 in the hUMSCs within a time span of $6 \mathrm{~h}$.

\section{Materials and methods}

Materials. Human umbilical cords obtained from women with full-term pregnancies whose babies were delivered by cesarean section were provided by the Obstetrics-Gynecology Department of the Second Affiliated Hospital of Hebei Medical University, Shijiazhuang, China. This study was approved by the Ethics Committee of the Second Hospital of Hebei Medical University. The single sialic acid four hexose ganglion glucoside ester sodium injection was obtained from Qilu Pharmaceuticals 
(Jinan, China); L-DMEM/F-12, H-DMEM/F-12 and fetal bovine serum (FBS) were obtained from Gibco (Carlsbad, CA, USA); penicillin-streptomycin was from Beijing Solarbio Science and Technology (Beijing, China) and paraformaldehyde was obtained from the Tianjin Institute of Chemical Preparations (Tianjin, China). Antibody against human epidermal growth factor EGF (huEGF) was purchased from Beijing Jiamei North Biological Technology (Beijing, China); FITC-CD19 (561295), FITC-CD34 (Rs-0646III), PE-CD11b (BYK-11127R), PE-CD73 (ANT-414), PE-CD90 (ab92574), PE-CD45 (PRO-482), PE-CD105 (CYT-424) antibodies and antibody to glial fibrillary acidic protein (GFAP; DIA-0302) were obtained from Becton-Dickinson (San Jose, CA, USA); antibody to neurofilament protein (NF-H; MAB1615) was from Cell Signaling Technology (Beverly, MA, USA); antibody to microtubule binding protein-2 (MAP-2; AB5622) was from Millipore (Billerica, MA, USA) and the PS immunohistochemistry kit was from Beijing Zhongshan Golden Bridge Biotechnology, Co. (Beijing, China).

\section{Methods}

Isolation and culture of hUMSCs. Following delivery, the collected umbilical cords were placed in high glucose Dulbecco's Modified Eagle's Medium (H-DMEM)/F12 culture medium under aseptic conditions, stored at $4^{\circ} \mathrm{C}$ and then transported to a cell culture room within $2 \mathrm{~h}$ for processing as follows: the umbilical cords were rinsed thoroughly with D-Hank's medium, and the umbilical artery and umbilical vein were removed after withdrawing the blood sample. The tissue was cut into $1-\mathrm{mm}^{3}$ sections, digested with $0.2 \%$ collagenase II and then placed into a culture flask containing $2 \mathrm{ng} / \mathrm{ml} \mathrm{EGF,} 20 \% \mathrm{FBS}, 25 \mathrm{mM}$ L-glutamic acid and $100 \mathrm{U} / \mathrm{ml}$ penicillin-streptomycin mixture in $\mathrm{H}-\mathrm{DMEM} / \mathrm{F} 12$. The flask was placed into an incubator at $37^{\circ} \mathrm{C}$ with $5 \% \mathrm{CO}_{2}$ and saturated humidity to obtain primary cells. When the cells achieved $80-90 \%$ confluency, they were passaged 1:3 following digestion with trypsin $0.25 \%$-ethylenediaminetetraacetic acid (EDTA) $0.2 \mathrm{~g} / \mathrm{l}$ into single cells. The culture medium used during passaging was H-DMEM/ F12 containing $100 \mathrm{U} / \mathrm{ml}$ penicillin streptomycin/mixture and $10 \%$ FBS.

Analysis of the cellular phenotype of hUMSCs. Single cell suspensions of hUMSCs in the logarithmic growth phase were prepared and then placed into 10 tubes at $1 \times 10^{6} /$ tube in phosphatebuffered saline (PBS). Mouse anti-human monoclonal antibodies to CD11-PE, CD45-PE, CD73-PE, CD90-PE, CD105-PE, HLA-DR-PE (P8950; Biotechnology LP and Sigma-Aldrich Co., St. Louis, MO, USA), CD19-FITC and CD34-FITC were added separately (each $5 \mu$ ) into 8 tubes. Anti-mouse IgG1-PE and antimouse IgG1-FITC antibody (each $7 \mu \mathrm{l}$ ) were added to the other 2 tubes as isotype controls. The cells and antibodies in all tubes were mixed thoroughly and incubated at $4^{\circ} \mathrm{C}$ for $30 \mathrm{~min}$. The cells were then rinsed in PBS and resuspended in $400 \mu$ of PBS prior to detection by flow cytometry.

Differentiation of hUMSCs into neuron-like cells. The hUMSCs of the third passage in the logarithmic growth phase were rinsed twice with PBS and digested with trypsin $0.25 \%$-EDTA $0.2 \mathrm{~g} / 1$. After terminating the digestion with FBS, the cells were centrifuged at $1,500 \mathrm{rpm}$ at $37^{\circ} \mathrm{C}$, resuspended in culture medium and seeded at $1 \times 10^{5} / \mathrm{ml}$ into 5 polylysine-coated 6 -well cell culture plates. The plates were divided randomly into 5 groups (groups A-E). When the cells achieved 70-80\% confluency, GM1 induction solution was added to groups A-D at concentrations of 50, 100, 150 and $200 \mu \mathrm{g} / \mathrm{ml}$, respectively. Only low glucose DMEM (L-DMEM) was added to group $\mathrm{E}$ (control). All of the treated plates were incubated for $6 \mathrm{~h}$ at $37^{\circ} \mathrm{C}$ with $5 \% \mathrm{CO}_{2}$ and saturated humidity, and the morphological changes in the cells were observed using an inverted phase contrast microscope (serial no. G02B21/00; Olympus Optical Company, Ltd., Tokyo, Japan) every hour during this incubation period.

Identification of differentiated cells. Following the induction of differentiation for $6 \mathrm{~h}$, the expression levels of the neuronal-specific proteins, MAP-2, NF-H and GFAP, were detected by immunohistochemistry as follows: the culture medium was discarded, and the cells were rinsed gently once with PBS prior to fixing with $4 \%$ paraformaldehyde for $20 \mathrm{~min}$ at room temperature. After this step and all subsequent steps, the cells were rinsed with PBS $(3 \times 5 \mathrm{~min})$ unless otherwise stated. The cell membranes were then disrupted with PBS containing $0.5 \%$ Triton $\mathrm{X}-100$ for $15 \mathrm{~min}$ at room temperature away from light. Following incubation with $3 \% \mathrm{H}_{2} \mathrm{O}_{2}$ at room temperature for $5 \mathrm{~min}$, normal goat serum was added for blocking at room temperature for $15 \mathrm{~min}$. The blocking solution was removed, and primary antibodies to MAP-2, GFAP and NF-H were then added (each diluted 1:200) in PBS. Following incubation at $4^{\circ} \mathrm{C}$ overnight, biotinylated secondary antibody (15180A01; Zhongshan Golden Bridge Biotechnology, Co.) was added to the cells followed by further incubation at room temperature for $15 \mathrm{~min}$, followed by the addition of horseradish peroxidase-conjugated streptavidin at room temperature for $15 \mathrm{~min}$. Color development was performed by adding freshly prepared diaminobenzidine (DAB; Zhongshan Golden Bridge Biotechnology, Co.) for $1 \mathrm{~min}$. After counterstaining with hematoxylin, the cells were rinsed repeatedly with water.

Following the induction of differentiation for $6 \mathrm{~h}$, the expression levels of the neuroal-specific proteins, MAP-2, NF-H and GFAP, were also detected by immunofluorescence staining as follows: the medium from the culture plates was discarded, and the cells were rinsed once gently with PBS and fixed with 4\% paraformaldehyde for $20 \mathrm{~min}$ at room temperature. The cells were then rinsed with PBS $(3 \times 5 \mathrm{~min})$ unless otherwise stated. The cell membranes were disrupted with PBS containing 0.5\% Triton X-100 for 15 min at room temperature away from light. PBS with $2 \%$ BSA was used for blocking at room temperature for $1 \mathrm{~h}$. Primary antibodies to MAP-2, GFAP and NF-H, each diluted at 1:200, were then added followed by incubation at $4^{\circ} \mathrm{C}$ overnight, followed by the addition of the secondary antibody at $37^{\circ} \mathrm{C}$ for $0.5 \mathrm{~h}$ in the dark. After the secondary antibody was removed, 4',6-diamidino-2-phenylindole (DAPI; Roche Diagnostics GmbH, Roche Applied Science, Mannheim, Germany) was added to stain the nucleus at room temperature for $15 \mathrm{~min}$. After the final rinse with PBS ( $3 \times 5 \mathrm{~min})$, the samples were examined under a fluorescence microscope (serial no. G02B21/00; Olympus Optical Company, Ltd.).

Determination of neuron-like cell ratios. A total of 10 non-overlapping fields in each group were selected under an inverted microscope, and the total number of cells and neuronlike cells was determined. The proportion of neuron-like cells in each group was analyzed using an $\chi^{2}$ test and the results are presented as the means \pm SEM. 

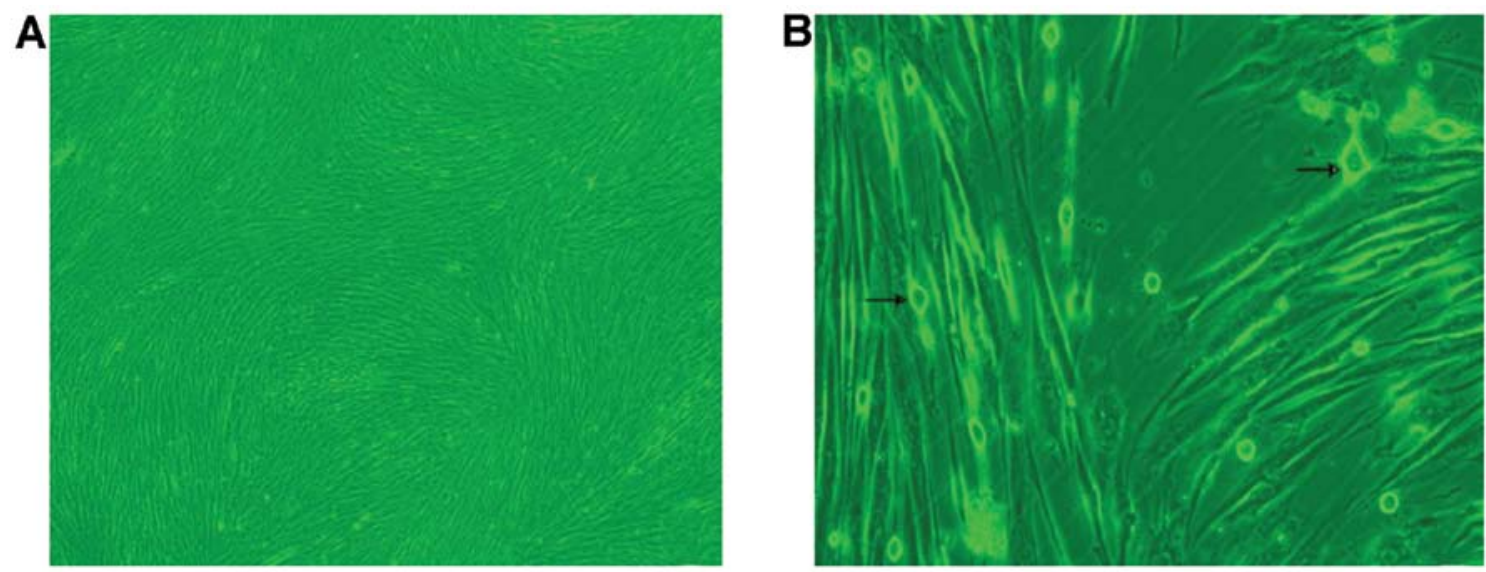

Figure 1. Morphology of human umbilical cord-derived mesenchymal stem cells (hUMSCs). (A) Spiral shaped hUMSCs before induction (x40 magnification). (B) Arrows indicate neuron-like cells after induction (x100 magnification).

Table I. Comparison of neuron-like cell antigen expression in hUMSCs induced by different concentrations of GM1 after $6 \mathrm{~h}$.

\begin{tabular}{lcc}
\hline Group & NF-H $(\%)$ & MAP-2 $(\%)$ \\
\hline $50 \mu \mathrm{g} / \mathrm{ml}$ & $14.43 \pm 1.15^{\mathrm{b}}$ & $14.12 \pm 1.36^{\mathrm{e}}$ \\
$100 \mu \mathrm{g} / \mathrm{ml}$ & $19.67 \pm 1.26^{\mathrm{a}, \mathrm{b}}$ & $19.92 \pm 2.79^{\mathrm{d}, \mathrm{e}}$ \\
$150 \mu \mathrm{g} / \mathrm{ml}$ & $37.44 \pm 2.23^{\mathrm{a}-\mathrm{c}}$ & $37.46 \pm 3.27^{\mathrm{d}-\mathrm{f}}$ \\
$200 \mu \mathrm{g} / \mathrm{ml}$ & $9.90 \pm 1.06^{\mathrm{a}}$ & $10.02 \pm 1.57^{\mathrm{d}}$ \\
Control & 0 & 0 \\
\hline
\end{tabular}

$\mathrm{F}_{1}=322.70 ;{ }^{a} \mathrm{P}<0.01 \mathrm{vs} .50 \mu \mathrm{g} / \mathrm{ml}$-treated group; ${ }^{\text {}} \mathrm{P}<0.01 \mathrm{vs} .200 \mu \mathrm{g} / \mathrm{ml}-$ treated group; ${ }^{c} \mathrm{P}<0.01$ vs. $100 \mu \mathrm{g} / \mathrm{ml}$-treated group; $\mathrm{F}_{2}=128.32$; ${ }^{\mathrm{d}} \mathrm{P}<0.01$ vs. $50 \mu \mathrm{g} / \mathrm{ml}$-treated group; ${ }^{\mathrm{P}} \mathrm{P}<0.01 \mathrm{vs.} 200 \mu \mathrm{g} / \mathrm{ml}$-treated group; ${ }^{\mathrm{P}} \mathrm{P}<0.01$ vs. $100 \mu \mathrm{g} / \mathrm{ml}$-treated group. hUMSCs, human umbilical cord-derived mesenchymal stem cells; GM1, monosialoteterahexosyl ganglioside; NF-H, neurofilament protein; MAP-2, microtubule-associated protein-2. Data represent the means \pm SEM from 4 different experiments.

Statistical analysis. SPSS 19.0 software was used to perform statistical analysis of the experimental data with a completely randomized design by analysis of variance among groups and the Student-Newman-Keuls (SNK) method (Q-test). A value of $\mathrm{P}<0.05$ was considered to indicate a statistically significant difference.

\section{Results}

Growth and morphological changes of hUMSCs. At $12 \mathrm{~h}$ after passaging the primary cultured cells (1:1), the majority of the cells became adherent, but were not outstretched and were triangular or diamond-shaped. The cell culture medium was replaced to remove the non-adherent cells after $24 \mathrm{~h}$. The adherent cells proliferated rapidly and became significantly larger, appearing uniformly as long fusiform shapes after $48 \mathrm{~h}$ in culture. On the 7th day, the cells reached $80-90 \%$ confluency in a radial or spiral pattern with no overlap. The majority of the cells had adhered to the plates after $24 \mathrm{~h}$ and achieved $80-90 \%$ confluency on the 7 th day, arranged in a radial or spiral pattern (Fig. 1A).
Cellular phenotype of the hUMSCs. The examination of the cellular phenotype of the hUMSCs at passage 2, 5 and 6 by flow cytometry revealed that the cells co-expressed CD105, CD90 and CD73, but not CD11b, CD34, CD19, CD45 or histocompatibility antigen HLA-DR (MHC-II) (Fig. 2).

Morphological and quantitative changes of neuron-like cells. Following induction with GM1 for $1 \mathrm{~h}$, some of the cell bodies in each experimental group contracted into elliptical shapes and then extended protuberances from two poles, which appeared like spindles. Group D had the most neuron-like cells, while group A had the least. Following the induction of differentiation for $3 \mathrm{~h}$, the neuron-like cells with longer protuberances gradually increased in all the experimental groups, but group D still had the most. Following the induction of differentiation for $4 \mathrm{~h}$, the number of neuronlike cells in groups A-C continued to increase and the cells appeared as bipolar or multipolar cells (Fig. 1B), while the number of neuron-like cells in group $\mathrm{D}$ began to decline. Following the induction of differentiation for $5 \mathrm{~h}$, the number of neuron-like cells did not increase further in groups A and $\mathrm{B}$, and some of the cells even became detached. However, group $\mathrm{C}$ had the most neuron-like cells, although some cells became detached as well. Group D had an abundant number of detached neuron-like cells. Following the induction of differentiation for $6 \mathrm{~h}$, no neuron-like cells were observed in groups A-C, and only a few of them were observed in group D. No obvious changes in the number of neuron-like cells were observed before and after sham-induction in the controls (group E). Fig. 3 illustrates the changes in the proportion of neuron-like cells in each experimental group over the induction period.

Immunocytochemical detection of neuron-specific markers. The immunocytochemical staining of NF-H and MAP-2 in the majority of neuron-like cells was positive, while GFAP was negative in the hMSCs treated for $6 \mathrm{~h}$ with various concentrations of GM1 (Fig. 4I). By contrast, no cells were positively stained for these markers in the control group, and immunocytochemical staining was negative when PBS was used instead of the primary antibody (Fig. 4J). 

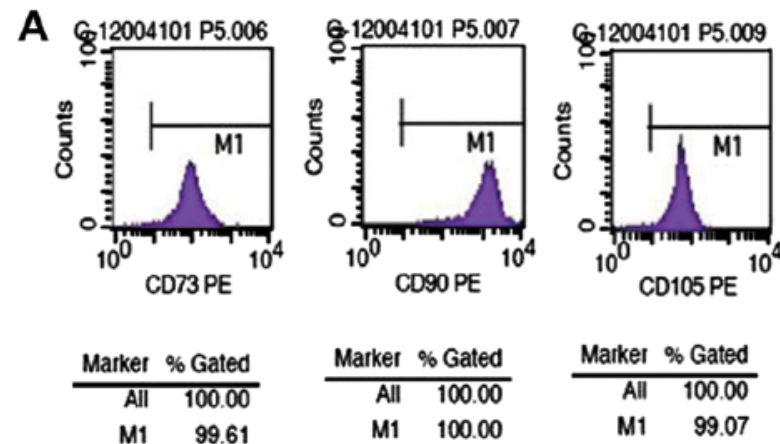

M1 99.07
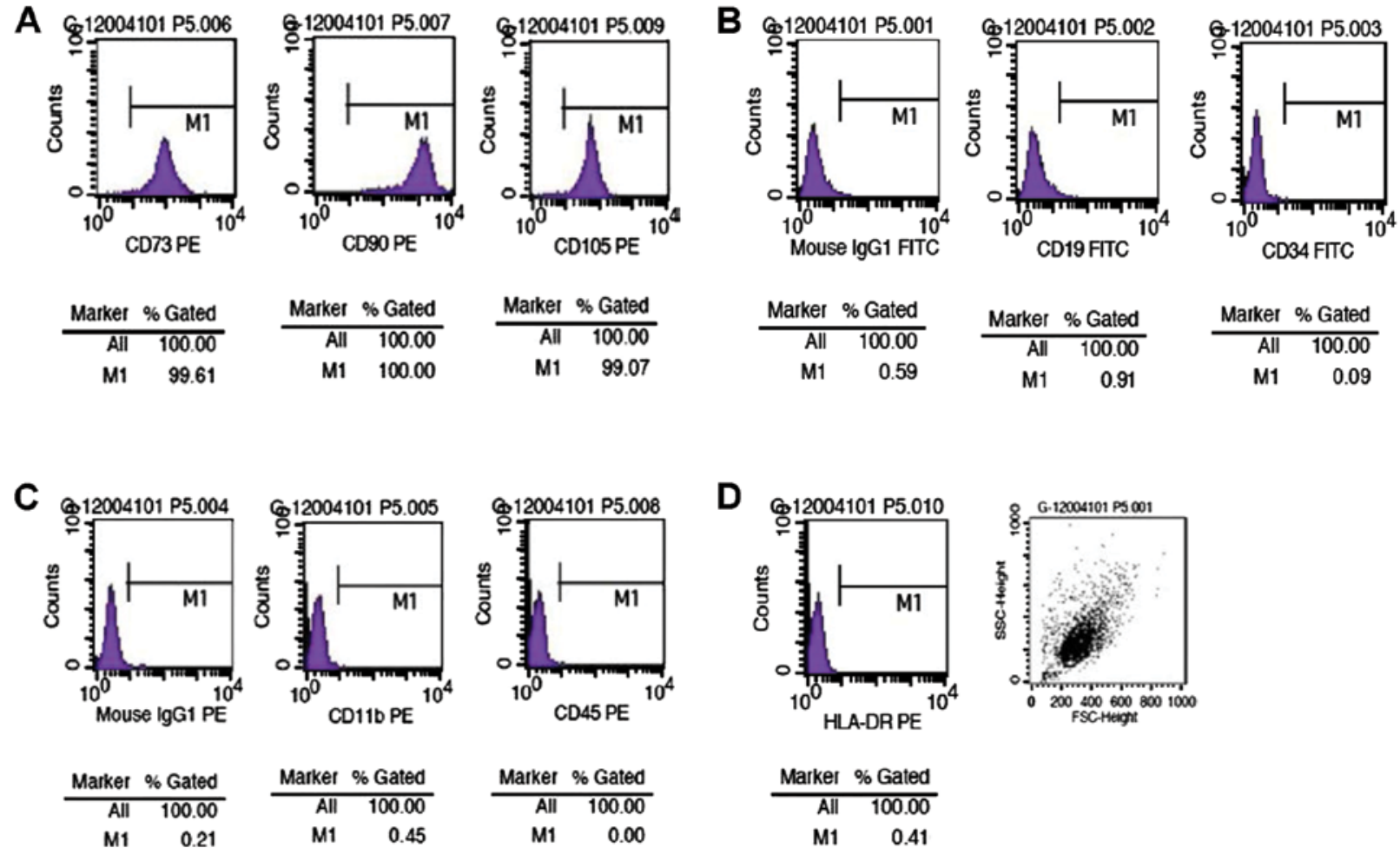

D

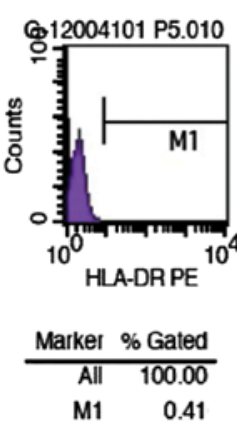

Figure 2. Surface marker expression in human umbilical cord-derived mesenchymal stem cells (hUMSCs) detected by flow cytometry. The percentages of hUMSCs which expressed (A) CD73, CD90 and CD105 were 99.61, 100 and 99.07\%, respectively. However, the percentages of hUMSCs which expressed (B and C) CD19, CD34, CD11b and CD45 and the expression of (B-D) isotype controls and HLA-DR were very low, which verifies that the cells we cultured were mesenchymal stem cells but not hematopoietic stem cells.

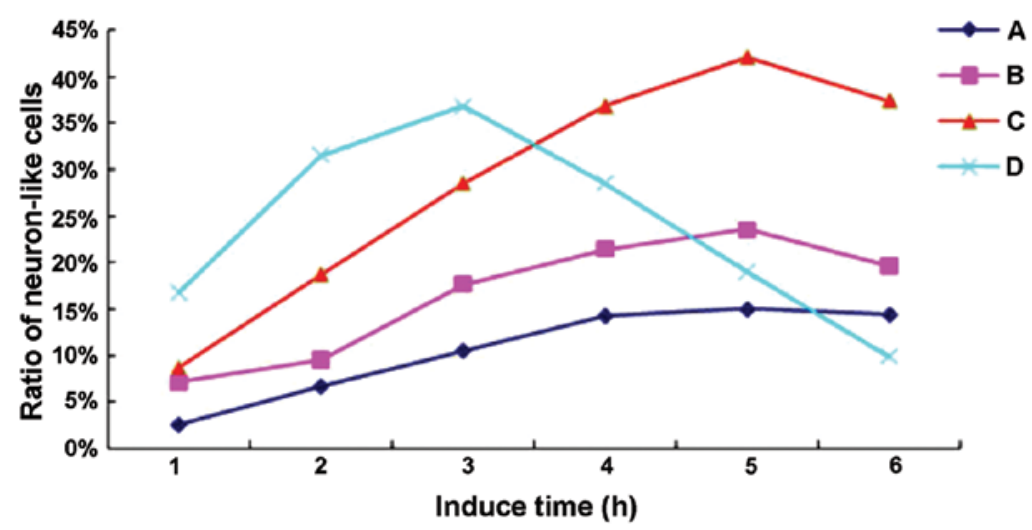

Figure 3. Proportion of neuron-like cells in each group over time following the induction of differentiation by monosialoteterahexosyl ganglioside (GM1).

\section{Discussion}

MSCs are adult stem cells derived from the mesoderm and can be isolated from tissues such as bone marrow, fat, placenta, umbilical cord blood and the umbilical cord. They have the potential of self-renewal, as well as high proliferative and multi-directional differentiation potential. Compared to stem cells derived from bone marrow, placenta and other tissues, hUMSCs have greater practical advantages. First, the umbilical cord as a source of stem cells has no associated ethical controversy and can be readily obtained at a low cost. Second, hUMSCs will not cause teratomas and have tumor suppressor properties. Since hUMSCs also have advantageous properties, such as low immunogenicity, migratory ability and genetic stability, as well as immune regulation, stroma support and paracrine functions, they hold great potential for use in clinical treatments (5). Studies on the transplantation of MSCs for the treatment of nervous system diseases have achieved encouraging results $(6,7)$. However, animal experiments have shown that only a small proportion of MSCs transplanted into damaged nerve tissue can differentiate into neuron-like cells $(8,9)$. In vitro experiments have also demonstrated that although the injured spinal cord tissue fluid can induce bone marrow-derived stem cells (BMSCs) to differentiate into neuron-like cells, the differentiation rate is not high $(10,11)$. Therefore, finding drugs which can induce or promote the differentiation of MSCs into neuronal cells is important. This study confirmed that ganglioside GM1 induced hUMSCs to 

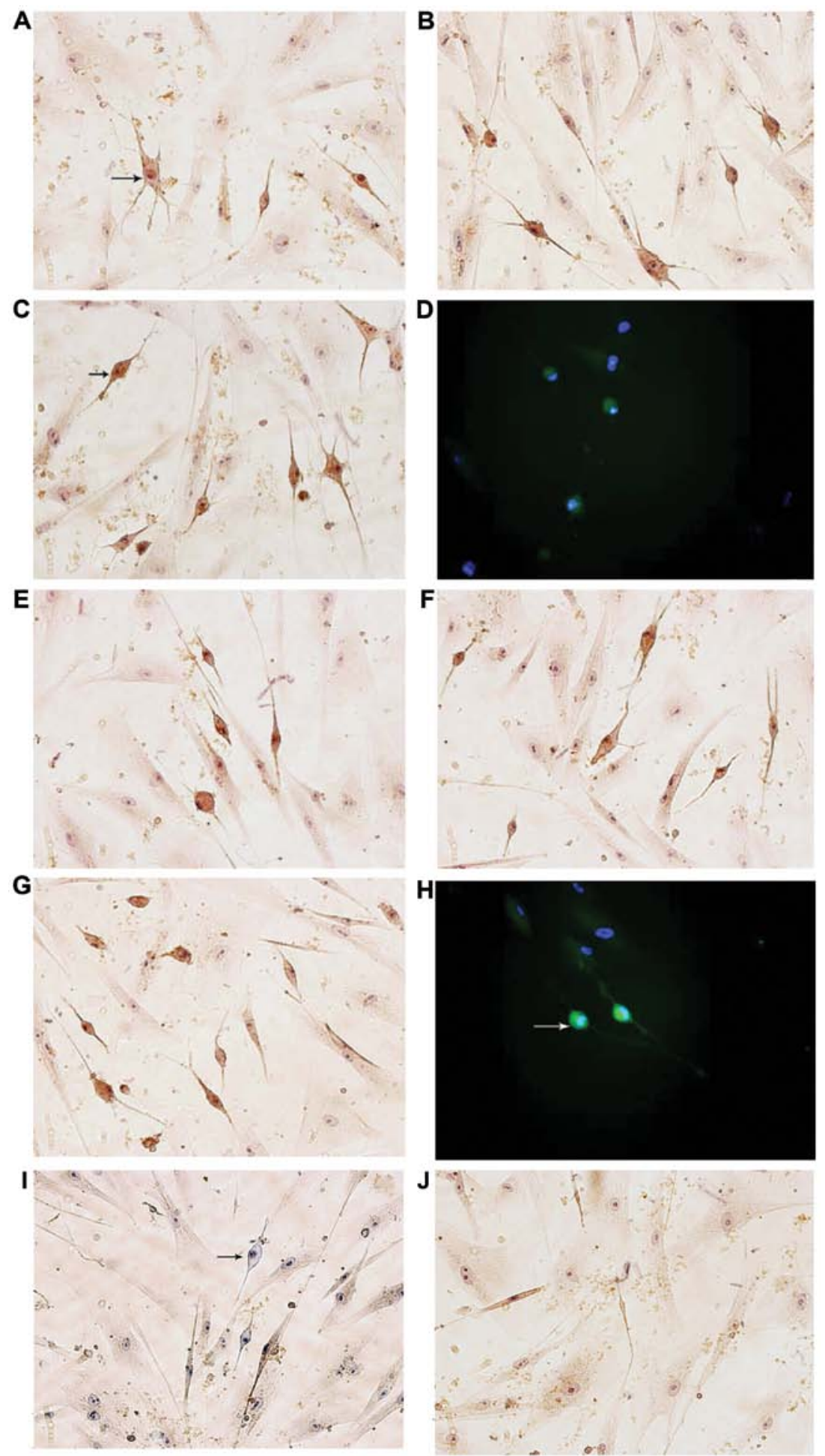

Figure 4. Staining for neuronal markers in human umbilical cord-derived mesenchymal stem cells (hUMSCs) induced to differentiate by monosialoteterahexosyl ganglioside (GM1). (A-D) Immunocytochemical detection of NF-H in treatment groups A-D, respectively. (E-H) Immunocytochemical detection of microtubuleassociated protein-2 (MAP-2) in treatment groups A-D, respectively. (D and H) Immunofluorescence detection of neuron-specific markers. Arrows indicate positive cells in panels $(\mathrm{A}, \mathrm{C}$ and $\mathrm{H}$ ). The arrow in panel I shows that the immunocytochemical staining of GFAP was negative. (J) No neuron-like cells were found in the control group and no cells were positively stained for neuronal marker (A-J, x200 magnification).

differentiate into neuron-like cells in vitro, characterized by the expression of the neuron-specific proteins, MAP-2 and NF-H, but not that of the astrocyte marker, GFAP.

Gangliosides are glycosphingolipids that contain sialic acid and are formed by hydrophobic ceramide and hydrophilic single sialic acid oligosaccharide chains. GM1 has been confirmed to have effects on cell-cell recognition and transmembrane signal transmission and adhesion. It can also regulate polypeptide growth factors to influence cell proliferation and promote cell maturation (12). Exogenous gangliosides can cross the blood 
brain barrier and promote nerve pullulation, axonal regeneration and synapse formation (13). They can also regulate and enhance the role of neurotrophic factors (14), resist apoptosis after nerve injury (15) and promote the proliferation of neural stem cells (16).

Zhao et al (17) demonstrated that sub-totipotent stem cells still retain sub-totipotent genes after the embryo has developed into an adult, but they gradually lose some of the original stem cell phenotype. If the tissue-specific gene expression program of such cells is activated in an appropriate microenvironment, they can differentiate into various histiocytes. As hUMSCs are sub-totipotent stem cells, GM1 may provide a microenvironment to activate the specific expression programs of nerve cells and thereby induce them to differentiate into neural cells. At least three mechanisms of activation are possible. First, GM1 may exert its effects on transmembrane ion flow in the hUMSCs. $\mathrm{Ca}^{2+}$ is a second messenger in cells, and changes in its concentration inside and outside of cells and its flow across the membrane, which are regulated by the $\mathrm{Ca}^{2+}$-ATP enzyme, may cause different biological consequences. Cui et al (18) indicated that exogenous GM3 has bidirectional regulatory effects on $\mathrm{Ca}^{2+}$-ATP enzyme activity, e.g., inhibition at low density and activation at high density. Liu et al (19) pointed out that TMP as a $\mathrm{Ca}^{2+}$ chelator may inhibit intracellular $\mathrm{Ca}^{2+}$ signaling to upregulate the gene expression of NSE and Nurrl, thereby accelerating the differentiation of hUMSCs into nerve cells. Thus, GM1 (especially at $150 \mu \mathrm{g} / \mathrm{ml}$ ) may inhibit the $\mathrm{Ca}^{2+}$-ATP enzyme at the cell membrane of hUMSCs, thereby reducing the concentration of intracellular $\mathrm{Ca}^{2+}$ and affect the signal transduction, ultimately inducing expression of neuron-specific genes and promoting differentiation into nerve cells. The second possible explanation for the mechanism of action by GM1 may be through its effects on nerve growth factor (NGF). GM1 can promote the generation of NGF (20), and the high concentration of neurotrophic factors may simulate a microenvironment during embryonic developmental stages of neurogenesis. A neurotrophic factor enriched environment can increase the expression of $\mathrm{MsC}$ membrane proteins TrkA, TrkB and $\mathrm{TkrC}$, which are neurotrophic factor receptors. The binding of neurotrophin with its receptor would initiate altered gene expression (21) and promote MSC differentiation into nerve cells. Finally, the impact of GM1 on hUMSCs may be on the length of neurites by activating an ectopic protein kinase on the surface of the cell membrane. This ganglioside sensitive protein kinase may serve as a transfersome to transmit signals from the outside of the cell to the inside, thus regulating the growth and length of the neurite.

In conclusion, gangliosides have been widely used as neuroprotective drugs and have played a positive role in clinic treatments. In this study, GM1 was shown to facilitate the development of neuron-like cells from primary hUMSCs in vitro. However, whether GM1 can induce hUMSCs transplanted in vivo to differentiate into neural cells effectively will require further study.

\section{Acknowledgements}

Project supported by the Topic Outstanding Youth Science Foundation of Natural Science Fund of Hebei (no.C2009001547), the Natural Science Fund of Hebei (no. H2013206399), the Medical Science Research Key Project of Hebei (no. 20130240).

\section{References}

1. Dominici M, Le Blanc K, Mueller I, Slaper-Cortenbach I, Marini F, Krause D, Deans R, Keating A, Prockop Dj and Horwitz E: Minimal criteria for defining multipotent mesenchymal stromal cells. The International Society for Cellular Therapy position statement. Cytotherapy 8: 315-317, 2006.

2. Baksh D, Yao R and Tuan RS: Comparison of proliferative and multilineage differentiation potential of human mesenchymal stem cells derived from umbilical cord and bone marrow. Stem Cells 25: 1384-1392, 2007.

3. Ning N and Chen NH: Progress in the research of ganglioside's biological activities. Sheng Li Ke Xue Jin Zhan 40: 24-30, 2009 (In Chinese).

4. Zhang Q and Zuo PP: Advances in the study of neuroprotective mechanisms of ganglioside GM1. Chin Pharmacol Bull 20: 1329-1333, 2004

5. Wang Y,Zhang JL, Hang XB, et al: Umbilical cord mesenchymal stem cell research present situation and the clinical treatment. Chongqing Med 42: 2161-2163, 2013.

6. Yu JX, Chen F, Sun J, Wang JM, Zhao QJ, Ren XJ, Ma FX, Yang SG, Han ZB and Han ZC: Umbilical cord mesenchymal stem cell transplantation for treatment of experimental autoimmune myasthenia gravis in rats. Zhongguo Shi Yan Xue Ye Xue Za Zhi 19: 744-748, 2011 (In Chinese).

7. Yang HQ, Wang YF, Li DS, et al: Application of umbilical cord mesenchymal stem cell transplantation in the treatment of two cases of hereditary spastic paraplegia. Chin J Tissue Eng Res 15: 167-170, 2011 (In Chinese).

8. Zhao ZM, Zhang QJ, Han ZC, et al: Improving functional outcome following bone marrow mesenchymal stem cells transplantation to injured spinal cord in rats. Chin J Neurosurg 19: 58, 2003.

9. Lee JB, Kuroda S, Shichinohe H, Yano S, Kobayashi H, Hida K and Iwasaki Y: A pre-clinical assessment model of rat autogeneic bone marrow stromal cell transplantation into the central nervous system. Brain Res Brain Res Protoc 14: 37-44, 2004.

10. Tang YA, Wang RS, Zhang C, et al: The inducting differentiation with the spinal cord extracts on rat bone mesenchymal stem cells in vitro. J Apoplexy Nerv Dis 20: 536, 2003.

11. Mei XF, Qin SJ, Fan GY, et al: Adult rat bone marrow stromal cells differentiate into neurons by the extracts of injured spinal cords. Chin J Clin Anat 23: 264-267, 2005.

12. Dawson TM, Hung K, Dawson VL, Steiner JP and Snyder SH: Neuroprotective effects of gangliosides may involve inhibition of nitric oxide synthase. Ann Neurol 37: 115-118, 1995.

13. Schengrund CL and Mummert CM: Exogenous gangliosides. How do they cross the blood-brain barrier and how do they inhibit cell proliferation. Ann NY Acad Sci 845: 278-284, 1998.

14. Levi-Montalcini R: The nerve growth factor 35 years later. Science 237: 1154-1162, 1987.

15. Zhuo Y, Liao WH, Wu BM, Wang $H$ and Chen $Z$ : The antiapoptosis effect of Ganglioside (GM1) after the spinal cord injury. Chin J Spine Spinal Cord 13: 536-538, 2003 (In Chinese).

16. Man Y, Li HW, Yang B, et al: Effects of different dose of ganglioside on proliferation and differentiation of nerve stem cells. Chin J Clin Rehabil 8: 4634-4635, 2004 (In Chinese).

17. Zhao CH, Fang BJ, Han Q, et al: Study about biological property of pluripotent stem cells and transplantation application. J Chin Microcircul 8: 345, 2004.

18. Cui W, Liu YK, Zhang XY, et al: The impact of ectogenic ganglioside GM3 on $\mathrm{Ca}^{2+}$-ATP enzyme and $\mathrm{Ca}^{2+}$ concentration in red blood cell cytoplasm. Acta Academica Med Shanghai 21: 385-387, 1994.

19. Liu YY, Zhao XX, Zhao HB, Ge BF, Liu XY and Chen KM: Tetramethylpyrazine induces the differentiation of mouse bone marrow-derived mesenchymal stem cells into nerve cells mediated by $\mathrm{Ca}^{2+}$ signaling. Gansu Nong Ye Da Xue Xue Bao 45: 1-5, 2010 (In Chinese).

20. Liberini P, Pioro EP, Maysinger D, Ervin FR and Cuello AC: Long-term protective effects of human recombinant nerve growth factor and monosialoganglioside GM1 treatment on primate nucleus basalis cholinergic neurons after neocortical infarction. Neuroscience 53: 625-637, 1993.

21. Yuan Y, Yang SY, Han ZC, et al: Amplification and differentiation towards neuron - like cells of human umbilical cord derived mesenchymal stem cells. Chin J Neuromed 5: 230-236, 2006. 